\title{
The Newly Established Unified Healthcare Fund (EOPYY): Current Situation and Proposed Structural Changes, towards an Upgraded Model of Primary Health Care, in Greece
}

\author{
Stefanos E. Karakolias*, Nikolaos M. Polyzos \\ Department of Social Administration and Political Science, Democritus University of Thrace, Komotini, Greece \\ Email: ${ }^{*}$ s.karakolias@gmail.com
}

Received 25 December 2013; revised 31 January 2014; accepted 10 February 2014

Copyright (C) 2014 by authors and Scientific Research Publishing Inc.

This work is licensed under the Creative Commons Attribution International License (CC BY). http://creativecommons.org/licenses/by/4.0/

\section{(c) (i) Open Access}

\begin{abstract}
Background: The National Organization for Healthcare Provision (EOPYY) constitutes simultaneously the monopsonistic healthcare insurer and a main provider of PHC in Greece. Currently, EOPYY is threatened by financial distress hence emerging a critical discussion on structural issues, providers' reimbursement and gatekeeping revision. Objectives: To conduct a detailed analysis of the Greek social health insurance and PHC in order to propose consolidation policies. Methods: Search for raw data domestically and best practices internationally. Results: In Greece, PHC provision is fragmented leading patients to more expensive hospital care. Family physicians are a small portion of total physicians which, in combination with the free choice policy, results in non-gatekeeping despite growing co-payments. This necessitates the creation of a PHC network between EOPYY's and NHS's units and contracted professionals. This first evaluation has also revealed an irrational use of consolidated resources, which we propose to normalize through a new global budget system. Conclusions: Greek health insurance needs an immediate reform through which EOPYY would become an efficient pool of public and social health inflows. Besides, we suggest gatekeeping to be activated, proclaiming new EOPYY contracts with general practitioners and family pediatricians, applying a stricter referral system and reforming the reimbursement system.
\end{abstract}

\section{Keywords}

EOPYY; Healthcare Fund; Health Insurance; Primary Health Care; Reimbursement

\footnotetext{
${ }^{*}$ Corresponding author.
}

How to cite this paper: Karakolias, S.E. and Polyzos, N.M. (2014) The Newly Established Unified Healthcare Fund (EOPYY): Current Situation and Proposed Structural Changes, towards an Upgraded Model of Primary Health Care, in Greece. Health, 6, 809-821. http://dx.doi.org/10.4236/health.2014.69103 


\section{Introduction}

Nowadays, the challenging economic environment motivates many governments in and beyond the European Union to increase efficiency and contain expenditure in health care systems. This evolution requires either unconventional reforms or reforms subsistent in nature. In this context, the 2011 reform in the Greek health social insurance market resulted in a unified central fund (National Organization for Healthcare Provision-EOPYY) [1], which simultaneously undertook the majority of PHC provision. Although EOPYY is considered to be the most promising reform after that of NHS (ESY), its performance doesn't seem to have met the stakeholders' expectations. This paper imprints the results of a relevant research project which was undertaken in order to record systems' and organizations' parallel to Greek PHC's current situation. Its first results revealed both a deficient and a non-integrated primary care function [2]. Moreover, the Greek government's supervision is restrictive, imposing a significant reduction in public health expenditure in the near future. This situation inspired us to conduct a comparative analysis on international health systems and health insurance organizations (e.g. AOKGermany, UNCAM-France, Kaiser Permanente-USA, FAHIF-Austria), in an effort to propose best practices with regard to structure, financing and providers' reimbursement. We conclude that major interventions are needed, including redefining and harmonization of the basic insurance package, supply control in the public and private sector, as well as control of the expected substitution of private health services with that of public. All of them are designed with the purpose of upgrading PHC around patients' needs [3].

\section{EOPYY}

\subsection{Establishment and Goals}

EOPYY is a public corporate body established under Greek Law 3918/2011 and it is supervised by the Ministry of Health (MoH) [until 1st April 2012 Ministry of Labour and Social Security (YPAKP) was a co-supervisor]. The organization launched its operations on 1st January 2012.

EOPYY's primary mission is the provision of health services to active members, pensioners and their family dependents registered to the merging healthcare funds [4]. EOPYY unified the majority of healthcare funds, amongst them being the Private Employees' Fund (IKA), the Public Employees' Fund (OPAD), the Farmers' Fund (OGA) and the self-employed/Entrepreneurs' Fund (OAEE). As a result, EOPYY covers over the $98 \%$ of the insured population (close to 11 million). This monopsony model is similar to the French National Union of Health Insurance Funds (UNCAM) [5], while significant similarities exist with the German "AOK Berlin" regional sickness fund [6] and the Federation of Austrian Health Insurance Funds (FAHIF) [7] respectively. For PHC, EOPYY also undertakes the operational coordination and the cooperation between (public and private) healthcare units and health professionals constituting the PHC network [4]. This role also includes regulative policy reform in quality and effectiveness, management and control of funding and the rational use of available resources. Moreover, EOPYY sets the major preconditions required for contractual commitment with providers of Public and Private primary and secondary care. The organization's role is also extended to provide key quantitative data to the MoH relevant to cost structure, beneficiaries' demographics and budget execution.

\subsection{Financing Health Services through EOPYY}

The United Regulation of Health Benefits [8] describes nine possible sources of financing EOPYY: 1) Employees' and employers' contributions; 2) Annual subsidies from the state budget up to $0.6 \%$ of GDP; 3) Income from any social resources; 4) Property revenues, return on capital and reserves; 5) Donations, legacies and bequests; 6) Financial revenues; 7) Income from fines and other penalties; 8) Revenues from services provided to privately and non-domestically insured population; and 9) Rebate inflows from pharmacies and pharmaceutical companies.

Table 1 represents the structure of EOPYY's financing. The initial projections of 2012 showed that total income would exceed 8 billion Euros, the majority of which would be derived from insurance contributions (56.6\%) and the government's involvement (18.6\%). Additional revenue would be achieved by adjusting the contributions of the four largest funds. However, this scenario was never achieved as the governments' subsidies were subsequently reduced by $0.4 \%$ (due to memorandum contractual conditions) and the partial readjustment of contributions (due to pressure from trade unions). Consequently, a revenue shortfall of over 2.5 billion Euros is estimated for 2012. Moreover, as shown in Table 2, the financial transfer between EOPYY and the unified 
Table 1. EOPYY’s revenue, initial 2012 budget (in million €).

\begin{tabular}{lcc}
\hline Inflows & $\mathbf{2 0 1 2}$ & \% of total \\
\hline Annual insurance contributions & 4565 & 56.6 \\
$\boldsymbol{\bullet}$ Employers & 2080 & 25.8 \\
$\boldsymbol{\bullet}$ Employees & 2485 & 30.8 \\
State subsides & 1500 & 18.6 \\
Adjustment of contributions of OPAD & 500 & 6.2 \\
Regulatory adjustment of contributions to $7.65 \%$ & $>1500$ & 18.6 \\
Total & $>\mathbf{8 0 6 5}$ & $\mathbf{1 0 0 . 0}$ \\
\hline
\end{tabular}

Source: [9].

Table 2. EOPYY’s revenue, revised 2012 budget (in million $€$ ).

\begin{tabular}{|c|c|c|c|}
\hline Inflows & 2012 budget & 2011 estimates & Deviation (\%) \\
\hline State subsides & 795.00 & 2015.77 & -60.6 \\
\hline Taxes, fees, charges & - & 41.85 & -100.0 \\
\hline Insurance contributions & 4634.65 & 5035.86 & -8.0 \\
\hline Income from business activities & 82.30 & 330.89 & -75.1 \\
\hline Surcharges, fines, penalties and fees & 29.30 & 48.99 & -40.2 \\
\hline Other income & 289.55 & 19.77 & 1364.6 \\
\hline Extraordinary income & 0.20 & 3.27 & -93.9 \\
\hline Income from loans & 0.45 & 0.15 & 200.0 \\
\hline Total & 5831.45 & 7496.55 & -22.2 \\
\hline
\end{tabular}

Source: [9].

funds was deficient by approximately 1.66 billion Euros. Data of Table 3 reveals that EOPYY's 2012 revenue budget (approximately 5.8 billion Euros) is insufficient to cover health expenditure of the insured population, whilst at the same time, there are significant liquidity problems. The expenditure budget is dominated mostly by pharmaceutical and hospital care, a phenomenon which in combination with under-financing reduces the PHC's ability to respond to the increased demand for its role as a gate-keeping tool.

Apart from the under-financing and low-liquidity problems, another emerging threat is that of rampant domestic unemployment that has two major characteristics: high levels of undeclared work (contribution evasion) and direct insurance reduction. Both of them imply a potential revenue shortfall. More specifically, at the end of 2011 the total number of EOPYY's beneficiaries was estimated at 11.35 billion, 6.38 billion directly insured (56\%) and 4.97 billion indirectly insured (44\%) [9]. This proportion is expected to change in the near future (2013-2014) towards a movement to the indirect system of health insurance (about $2 / 3$ of total beneficiaries). At this point, another distortion arises from the fact that the total insured population exceeds the resident population recorded by the 2011 census (10.81 billion) [10]. This deviation is explained by the phenomenon of double insurance and/or the abstention from census. Despite the distortions described above, EOPYY is not threatened by social obsolescence this due to beneficiaries not having the right of statutory health insurance from another insurer. This kind of "free choice" refers to a state-controlled competition applied both in the Netherlands [11] and Germany [12].

The most recent projections on EOPYY's revenue budget are summarized in Table 4. In 2013 the total revenue is budgeted at least 6.2 billion Euros, the largest part of which comes from insurance contributions (70\%) and state subsidies (18\%). However, contribution evasion still exists and implies a revenue loss approximating 20\% (800 million Euros). The expenditure budget of the same year (Table 5) shows that PHC services, 
Table 3. EOPYY's expenditure, 2012 budget (in million €).

\begin{tabular}{|c|c|c|c|c|}
\hline Outflows & 2012 budget & Paid & Outstanding (5/2012) & Total \\
\hline Pharmaceutical expenditure & 2250.0 & 1229.9 & 350.0 & 1579.9 \\
\hline Public hospitals & 1050.0 & - & 320.0 & 320.0 \\
\hline Private hospitals & 585.0 & 93.8 & 90.0 & 183.8 \\
\hline Diagnostic centers & 187.5 & 41.3 & 40.0 & 81.3 \\
\hline Physicians & 152.0 & 16.0 & 10.0 & 26.0 \\
\hline Additional (rehabilitation) care & 173.0 & - & - & - \\
\hline Dentistry-preventative medicine & 247.1 & - & - & - \\
\hline Other operational costs & 896.8 & - & - & - \\
\hline Expenditure of insured of OPAD & - & - & 110.0 & - \\
\hline Total & 5541.4 & 1381.0 & 810.0 & 2191.0 \\
\hline
\end{tabular}

Source: [9].

Table 4. EOPYY’s revenue, 2013 and 2014 budget (in million €).

\begin{tabular}{|c|c|c|c|c|}
\hline Inflows & $2013^{\mathrm{a}}$ & $\%$ of total & $2014^{\mathrm{b}}$ & $\%$ of total \\
\hline Annual insurance contributions & 4355 & 70.30 & 4350 & 39.47 \\
\hline Social resources & 3 & 0.05 & - & - \\
\hline Government's subsidies for benefits and operational costs & 1108 & 17.89 & 2200 & 19.96 \\
\hline Return on assets & 53 & 0.86 & 110 & 1.00 \\
\hline Revenue from services provided to "third" parties (participated insurance funds) & 364 & 5.88 & 360 & 3.27 \\
\hline Rebate from pharmaceutical companies & 250 & 4.04 & 200 & 1.81 \\
\hline Other & 62 & 1.00 & - & - \\
\hline Government's subsidies for payroll & & & 3200 & 29.04 \\
\hline Confrontation of contribution evasion & & & 600 & 5.44 \\
\hline Total & 6195 & 100.00 & 11,020 & 100.00 \\
\hline
\end{tabular}

${ }^{\mathrm{a}}$ /2013 projections. Source: [13]; ${ }^{\mathrm{b}}$ Proposal.

represented by total non-hospital services, absorb 1/6 of the total expenditure (at least 1 billion Euros). Additionally, NHS hospital expenditure decreased $10 \%$ on average per year since 2010. In 2009, expenditure was over 6 billion Euros, in 2012 over 5 and 2013 less than 5 (only 1/5 of this has been reimbursed by EOPYY under a DRG scheme which was established in parallel). Pharmaceutical expenditure had similar reductions. Pharmaceutical expenditure blowouts have over the past decades been attributed to many factors [14]. Expenditure gradually decreased from 2009 to 2012 (over $10 \%$ on average per year). The demanding effort to rationalize pharmaceutical expenditure in Greece appears to be on course, based on results of price regulation, being achieved in a stressful and volatile environment, caused by the Greek economic crisis. However, the financing gap remains the organization's "open wound". Another important issue is that this gap passes on the private sector, disrupting the providers' cash cycles, through extraordinary payment delays [15] [16].

\section{Provision of PHC through NHS and EOPYY}

The Greek legislative framework [4] [17] specifies that PHC is provided by publicly-owned entities (hospitals, health centers etc.), privately-owned entities (private hospitals, diagnostic laboratories etc.), EOPYY's units and contracted with EOPYY health professionals. Table 6 summarizes the manpower and structures of the Greek 
Table 5. EOPYY’s expenditure, 2013 and 2014 budget (in million $€$ ).

\begin{tabular}{|c|c|c|c|c|}
\hline Outflows & $2013^{\mathrm{a}}$ & $\%$ of total & $2014^{\mathrm{b}}$ & $\%$ of total \\
\hline Pharmaceutical expenditure & 2621 & 44.17 & 2420 & 23.27 \\
\hline Transfers to private hospitals & 732 & 12.34 & 750 & 7.21 \\
\hline Diagnostic centers & 450 & 7.58 & 300 & 2.88 \\
\hline Physicians & 110 & 1.85 & 150 & 1.44 \\
\hline Additional (rehabilitation etc.) care & 150 & 2.53 & 150 & 1.44 \\
\hline Dentistry-preventative medicine & 230 & 3.88 & 200 & 1.92 \\
\hline Upcoming payments & 364 & 6.13 & 350 & 3.37 \\
\hline Other expenses & 100 & 1.69 & - & - \\
\hline Transfers to public hospitals & 1150 & 19.38 & 1150 & 11.06 \\
\hline Administrative expenses & 2 & 0.03 & 3 & 0.03 \\
\hline Payroll (central EOPYY) & 25 & 0.42 & 27 & 0.26 \\
\hline Additional transfers to hospitals & & & 3900 & 37.5 \\
\hline Extra GPs & & & 100 & 0.96 \\
\hline Rural health centers (NHS) & & & 250 & 2.40 \\
\hline Urban health centers (EOPYY, proposed for merging to NHS) & & & 200 & 1.92 \\
\hline Uninsured and destitute benefits & & & 300 & 2.88 \\
\hline Regional administration—payroll (EOPYY) & & & 150 & 1.44 \\
\hline Total & 5934 & 100.00 & 10,400 & 100.00 \\
\hline
\end{tabular}

${ }^{\mathrm{a}} 2 / 2013$ projections. Source: [13]; ${ }^{\mathrm{b}}$ Proposal.

PHC at the beginning of 2013. Unfortunately, the exact quantification of the manpower of public and private hospitals and other private structures was impossible, due to lack of official data provided by MoH and relevant researches.

With respect to the composition of physicians in Greece, there is a small proportion of GPs in the total number of PHC physicians (9.4\%), whilst the corresponding proportion is even lower regarding the contracted with EOPYY physicians (7.7\%) (Table 6 calculations). These figures overestimate the current situation comparing with OECD's data whereby total GPs occupy only 5\% of total Greek physicians (including those of secondary and tertiary care) [16]. That reveals a significant deviation from advanced European health systems whose (EU25) average reaches 30\% [19]. In other words, the figures above reinforce our concerns about both the relaxed participation of family physicians in the Greek NHS and their low contribution to the gate-keeping mechanism.

Furthermore, the figures of Table 6 indicate that Greek PHC has adopted a physician-driven organizational structure, since physicians outnumber by far all other health professionals. This is endorsed by quantitative data i.e. Greece has by far the highest number of physicians per capita among European countries (6.1 physicians per 1000 population in 2010) [19]. On the other hand, the density of nursing manpower of PHC providers is markedly lower in Greece (0.46 in PHC (Table 6), 3.3 totally [19]). Compounding this shortfall, nursing staff have limited and inflexible responsibilities which implies a regressive nursing management [20]. Finally, it should be taken into account that apart from these 26.000 total PHC staff at NHS and EOPYY, an equivalent number of professionals work as solo practice (doctors or other health professionals) or group practice within diagnostic centers. Private payments on PHC estimated another billion Euros in Greece [2].

The provision of PHC in Greece has additional features which are irregular and uncommon. First of all, PHC controlling authorities have not managed to apply a rational geographical distribution of contracted EOPYY physicians. Their concentration in Athens and Thessaloniki respectively (the two most congested cities) is approximately $62 \%$ of total physicians, whist at the same time there is complete lack of some specialties across the 
Table 6. Manpower and units of Greek PHC at NHS and EOPYY.

\begin{tabular}{|c|c|c|c|}
\hline Assigned to & PROFESSIONALS & Number & Per 1000 population \\
\hline EOPYY $^{\mathrm{c}}$ & Independent GPs & 420 & 0.039 \\
\hline EOPYY $^{\mathrm{e}}$ & GPs at EOPYY's units & 500 & 0.046 \\
\hline \multirow[t]{2}{*}{$\mathrm{NHS}^{\mathrm{e}}$} & GPs at health centers and regional offices & 500 & 0.046 \\
\hline & Total GPs & 1420 & 0.131 \\
\hline EOPYY $^{\mathrm{c}}$ & Independent specialists & 5066 & 0.468 \\
\hline EOPYY & Specialists at EOPYY's units & 5589 & 0.517 \\
\hline \multirow[t]{2}{*}{$\mathrm{NHS}^{\mathrm{e}}$} & Specialists at health centers and regional offices & 1400 & 0.129 \\
\hline & Total specialists & 12,055 & 1.115 \\
\hline \multirow[t]{2}{*}{$\mathrm{NHS}^{\mathrm{e}}$} & Resident and rural physicians (non-specialists) & 1630 & 0.151 \\
\hline & Total physicians & 15,105 & 1.397 \\
\hline EOPYY & Nurses at EOPYY's units & 2841 & 0.263 \\
\hline \multirow[t]{2}{*}{$\mathrm{NHS}^{\mathrm{e}}$} & Nurses at health centers and regional offices & 2113 & 0.195 \\
\hline & Total nurses & 4954 & 0.458 \\
\hline EOPYY & Other staff at EOPYY's units & 1373 & 0.127 \\
\hline \multirow[t]{2}{*}{$\mathrm{NHS}^{\mathrm{e}}$} & Other staff at health centers and regional offices & 2325 & 0.215 \\
\hline & Total other staff & 3698 & 0.342 \\
\hline \multirow[t]{4}{*}{ EOPYY $^{\mathrm{c}}$} & Physiotherapists and other health professionals & 2125 & 0.196 \\
\hline & Total professionals (excluding physicians) & 10,777 & 0.996 \\
\hline & Total professionals & 25,882 & 2.393 \\
\hline & UNITS & Number & Per 1000 population \\
\hline EOPYY & Diagnostic laboratories (80\% solo and 20\% group practice) & 2402 & 0.222 \\
\hline EOPYY $^{\mathrm{c}}$ & Rehabilitation and recovery centers & 40 & 0.004 \\
\hline EOPYY $^{\mathrm{c}}$ & Daycare centers & 33 & 0.003 \\
\hline EOPYY $^{\mathrm{c}}$ & Polyclinics & 36 & 0.003 \\
\hline \multirow[t]{2}{*}{ EOPYY $^{\mathrm{p}}$} & EOPYY’s units (polyclinics and medical offices) & 400 & 0.037 \\
\hline & Other & & 0.000 \\
\hline NHS $^{p}$ & - Health centers (simple, urban and special purpose) & 220 & 0.020 \\
\hline $\mathrm{NHS}^{\mathrm{p}}$ & - Regional offices (simple, multi and special purpose) & 1530 & 0.141 \\
\hline $\mathrm{NHS}^{\mathrm{p}}$ & - Public hospitals' outpatient clinics & 131 & 0.012 \\
\hline \multirow[t]{2}{*}{ NHS } & - Private hospitals' outpatient clinics & 162 & 0.015 \\
\hline & Total units & 4954 & 0.458 \\
\hline
\end{tabular}

${ }^{\mathrm{c} C o n t r a c t u a l ~ r e l a t i o n s h i p ~(s e l f-e m p l o y e d ~ a n d ~ e n t e r p r i s e s) ; ~}{ }^{\mathrm{e}}$ Employees (salaried); ${ }^{\mathrm{P}}$ Property relationship; Source: [4] [13] [18]. 
whole country with the exception of the five largest counties [4]. That means that urban areas tend to attract both providers and patients [21]. Internal medicine, cardiology, obstetric-gynecology, general practice and orthopedics are classified as the five most populous specialties corresponding to $63 \%$ of total physicians.

Another problem is the subordinate role of health centers and regional offices in spite of the growing demand for them. Despite the positive steps of decentralization and regionalization of administration of the health care system, these units remain substandard, including personnel shortage, inadequate resources and a lack of medical record documentation [22]. Nursing staff employed in these centers and offices are to large extent untrained, playing mainly traditional/tight roles [23].

An interesting evolution deriving from the current domestic debt crisis is the structural change in the demand for health services. More specifically, patients are led to public services mainly due to the negative impact of crisis on their disposable income. For example, laboratory tests in public units increased by $18 \%$ while visits to health centers increased by $22 \%$ (2010-11 change), signifying a significant market share loss to private diagnostic laboratories [24]. Subsequently, this evolution requires managerial intensification to actively curb "clientalism”, a phenomenon that has dominated the public sector [25].

Moreover, the gate-keeping mechanism functions poorly not only because of the shortage of GPs, nurses and midwives, but also because of the "free choice" institution [26], i.e. the chance allowed to the insured population to choose freely any provider of NHS or EOPYY. France (UNCAM) [5] and Austria (FAHIF) [7] apply a similar system. Generally, Greek citizens seem to prefer inpatient/hospital PHC services as they consider them more effective. Typically, $9 \%$ of them visit public hospitals' outpatient clinics, $11 \%$ health centers and regional offices, $30 \%$ EOPYY's units, $25 \%$ contracted professionals, $20 \%$ private hospitals and $5 \%$ other structures [27]. The "free choice" perception is highlighted further with the additional healthcare load of non-insured and illegal immigrants who receive care (mainly public) [28], whilst visits of foreigners to outpatient services are not recorded [29].

\section{A Proposed Model for PHC Provision and Financing}

Having already noticed the organizational and financial weaknesses, the starting point of our proposal revolves around EOPYY's conversion from a provider to a "contractual agency" which would continue to act as monopsony and subsequently be the chief receiver of total public health financing. For example, contributions should be collected either directly by EOPYY or indirectly by pension funds. In the latter case the transfer to EOPYY must be immediate in an online monthly basis.

As shown in Table 4, the proposed consolidated model results in annual revenue of about 11 billion Euros during 2014. To ensure the feasibility of this plan several actions are required: 1) EOPYY should take on the pension funds' role of contribution evasion management and impose stricter fines. Given that contribution evasion reaches 20\% in 2013 [30] or close to 800 million Euros (see Table 4), its effective management could minimize evasion at $6.0 \%$ - 6.5\%, resulting in additional revenue of up to 600 million Euros; 2) EOPYY should also be the controlling agent for the receipt of state payroll subsidies for NHS employees, compensating NHS hospitals on the total cost of the newly established DRG system [31] that is currently under relative revision (the relevant revenue is estimated to be at least 3 billion Euros, covering over 50\% of NHS Hospitals expenditure); 3) Government subsidies for benefits and operational costs of NHS units must be transferred to EOPYY for the same reason resulting in a further 2 billion Euros for health care coverage in 2014; 4) Return on assets could be doubled (from 53 to 110 million Euros) by outsourcing the assets management to private corporations. To account for the possibility of revenue shortfalls, other measures such as earmarked taxes or increase of insurance contributions could be taken respectively.

This proposal allows for PHC provision in Greece to be undertaken by the professionals and units as indicated in Figure 1 and should be financed under an annual global budget taking into account geographical distribution (population etc.) and performance data (see below). More specifically:

Up to 200 merged NHS health centers and 1500 regional offices (220 health centers and 1530 regional offices in 2013) both of which are staffed by 3500 physicians (about 500 of which are GPs initially), 2100 nurses and 2300 allied administrative and technical staff (7900 total staff). Up to 200 merged EOPYY (merging in NHS) units (400 polyclinics and medical offices in 2013) which are staffed by 6000 physicians (about 500 of which are GPs initially), 2800 health staff and 1400 allied administrative and technical staff (10,300 total staff). 7000 contracted physicians implying that additional contracts and a reallocation of human resources are needed in 2014. Additional contracts refer to an extra 580 GPs (420 in 2013) and an extra 794 pediatricians (206 in 2013). Obviously the purpose is to boost the family physician (GP) and the family pediatrician primary healthcare delivery. 


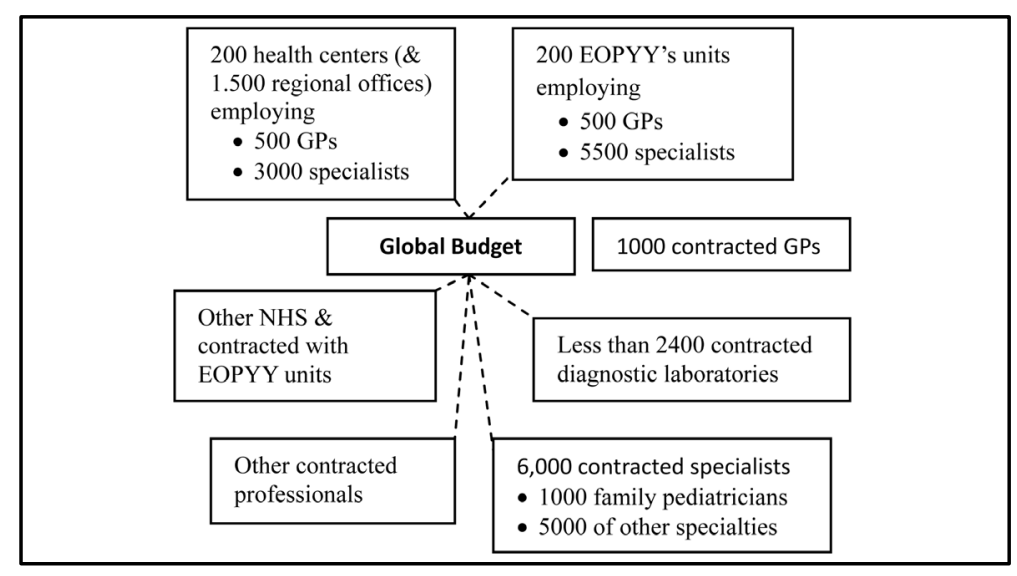

Figure 1. Proposed PHC network in Greece.

2400 diagnostic laboratories contracted with EOPYY (reductions will be based on quality standards and certification criteria. This should be implemented immediately). Other contracted professionals (i.e. pharmacists, physiotherapists, etc.). Other NHS (outpatient clinics) and contracted with EOPYY (rehabilitation, recovery and daycare centers).

Regarding health care units, our proposal estimates the need of no more than 400 health centers (200 NHS mainly in agricultural and semi-urban areas and 200 EOPYY in urban areas), including total mergers of small EOPYY urban clinics, while no more than 1500 agricultural medical offices should remain to service islands, mountainous villages and other isolated areas. This adjustment fits with the new 350 municipalities of Kallikratis plan, plus a further 50 in the large metropolitan areas-cities [2].

Summarizing, PHC in Greece will be provided mainly by 16,500 physicians. The role of family physician will be constantly upgraded with 2000 family physicians (1000 self-employed, plus 1000 salaried, all under an extra pay-for-performance system) and 1000 family pediatricians in the beginning of 2014. Their numbers should be further increased in 2015-2016 in an attempt to get closer to the international standards (paid on a capitation basis).

Concluding, Table 5 represents the proposed expenditure budget of 2014. Among the same outflows with that of 2013, payments to contracted physicians are expected to rise by 40 million Euros due to the contracts with additional GPs and pediatricians. However, the sum of the corresponding to 2013 outputs will fall down at about 5.5 billion Euros after the effective activation of the gate-keeping mechanism. In 2014, EOPYY's total expenditure will approach 10.4 billion Euros, entailing a surplus of about 600 million Euros (paid for past debts) coming from social insurance evasion.

According to the proposed model, PHC will continue to absorb over 1 billion Euros hence 1/10 of total expenditure. This amount will be allocated regionally and through the PHC providers' network based on global budgets that are represented totally in Table 7. During the preparation of the global budgets, we only considered catchment population and utilization criteria, whilst further we propose a Resources Allocation Working Party (RAWP) formula [32] for the future, in which morbidity and other health indices which are not available now should be included, as well as poverty or unemployment ratios. As follows, NHS providers absorb over $20 \%$, EOPYY's units under 25\%, while contracted professionals and units 55\% of the total budget.

\section{Reimbursement Model of PHC Providers}

Greek PHC providers are reimbursed in a quite simplified manner. Self-employed health professionals and enterprises, contracted with EOPYY (physicians, physiotherapists, rehabilitation centers etc.), are reimbursed on a feefor-service payment based on the State Invoice of Medical Procedures [1]. Simultaneously, there is an additional 10 Euros co-payment for each visit to a contracted physician's office, a mixed system also found in the Netherlands (€9 per visit) [33]. It's important to note that there is a maximum remuneration of 200 visits per month for each physician. That causes another phenomenon whereby physicians ask patients for out-of-pocket payment with the pretense that they have exceeded the ceiling (under-the-table payments [34]). This model in combination with poor auditing in some cases creates favorable conditions for wasting resources and induced demand. On the other 
Table 7. Proposed PHC global budget per health provider and district (in million $€$ ).

\begin{tabular}{|c|c|c|c|c|c|c|c|c|}
\hline \multirow{2}{*}{ Provider } & \multicolumn{7}{|c|}{ Health districts } & \multirow[b]{2}{*}{ Total } \\
\hline & $1^{\text {st }}$ & $2^{\text {nd }}$ & $3^{\text {rd }}$ & $4^{\text {th }}$ & $5^{\text {th }}$ & $6^{\text {th }}$ & $7^{\text {th }}$ & \\
\hline Health centers \& regional offices & 20 & 35 & 25 & 25 & 35 & 45 & 15 & 200 \\
\hline EOPYY's units & 85 & 15 & 30 & 30 & 35 & 40 & 15 & 250 \\
\hline Contracted generalists & 30 & 10 & 10 & 10 & 15 & 20 & 5 & 100 \\
\hline Contracted specialists & 50 & 15 & 15 & 15 & 20 & 30 & 5 & 150 \\
\hline Diagnostic laboratories & 69 & 20 & 35 & 35 & 36 & 37 & 18 & 250 \\
\hline Others & 16 & 5 & 5 & 5 & 8 & 9 & 2 & 50 \\
\hline Total & 270 & 100 & 120 & 120 & 149 & 181 & 60 & 1000 \\
\hline Catchment population (in millions) & 3.00 & 1.05 & 1.30 & 1.30 & 1.60 & 1.90 & 0.65 & 10.80 \\
\hline
\end{tabular}

hand, every employee at hospitals, health centers, EOPYY's units etc. works under exclusive employment and has a fixed salary, leading in unofficial payments too [35]. Co-payments when using NHS services are also used in order to face the overconsumption of them, following the corresponding French system. These payments have either the form of fixed percentage rates on the total cost (i.e. 25\% for pharmaceutical care, 15\% for laboratory tests) or the form of a flat rate of 5 Euros per visit to health centers and outpatient clinics. Hence, in Greece there is complete lack of major cost-containment policies (i.e. per case or capitation reimbursement) and pay-for-performance mechanisms. International literature suggests that the institution of family physician requires the application of capitation payments [36], however they can lead physicians to risk-selection [37]. Similarly, per case reimbursement can be complementary to a fee-for-service or capitation reimbursement in case of urgent containment of health expenditure [38]. However, this financial orientation may cause several negative impacts on quailty and effectiveness of health services. In this context, pay-per-performance systems can be applied [39] providing monetary incentives to physicians [40].

Our first proposal is associated with the upgrade of the gate-keeping role of GPs-family practitioners and pediatricians. Specifically focused on the reimbursement method, contracted first contact physicians (GPs and family pediatricians) is proposed to be reimbursed with $€ 20$ per capita (registered population between 1000 and 2000 ). That assumes provision of 8-hour services daily (4 hours in the morning and 4 hours in the afternoon, on working days) as well as 4 calls per month (on non-working days). Additional payments must be established as an incentive for the simultaneous management of multiple health problems in the same patient episode of care and the necessary preventive medical practices and activities (health education, management of major risk factors, etc.). These additional payments imply a pay-for-performance scheme similar to this applied by UNCAM through CAPIs (Contrats d' amelioration des pratiques individuelles) [5]. Additional payments will be established in case of screening ( $€ 5$ per case), elderly people over 65 care (€5 per capita), chronically ill population care (€5 per capita) and home visits (€5 per visit, maximum 3 visits per year). Furthermore, first contact physicians should receive a type of allowance for 24-hour services provision to beneficiaries. Extra payments are also necessary in case of counteracting mental or other illnesses intensified mainly due to current financial crisis [41].

It is also necessary to introduce a co-payment of 5 Euros (in patient's charge) for each visit to specialists without a referral from a family physician or pediatrician or any other nominated specialist. As hinted above, beneficiaries could visit specialists without charge only after referral by first contact physicians. This policy should be applied only to (directly and indirectly) insured population, while non-charging of uninsured population will be hedged by part of the contribution evasion confrontation outcome. On the other hand, contracted specialists and other health professionals will continue to be reimbursed on a fee-for-service basis, specifying visiting hours and/or a higher upper ceiling of visits per month (up to 300 visits), but an inspiring from AOK adjustment to global budgets (of Table 7) is necessary. As a result, specialists' payments depend not only on the volume of services they provide but also on the global budget of the health district they are registered to, as well as their annual cumulative reimbursement cannot exceed 150 million Euros. Another high co-payment (about 50\%) is needed for laboratory and radio diagnostic tests or visits to health professionals without a referral from a contracted physician (non-charging for uninsured population is applied again). A same purpose but lower (20\%) co-payment is charged 
in Austria [7].

GPs of health centers, regional offices and EOPYY's polyclinics will maintain their fixed salary, but they will also be able to sign contracts with EOPYY. These contracts will ensure them a $€ 10$ per capita over 1000 catchment population, as an incentive to attract patients. Moreover, they are beneficiaries of additional payments like those of self-employed GPs.

Finally, per case reimbursement could be introduced into health centers and EOPYY's units through a system of prospective remuneration in accordance with Diagnosis Related Groups (DRGs) principles. A reliable and accurate prospective model structured for PHC is that of Ambulatory Patient Groups (APGs) [42]. Patients belonging to the same group have similar clinical characteristics and similar resource use and therefore cost. Obviously, some variation in resource use among patients within the same group cannot be excluded, as patients cannot be identical. Nonetheless, the exact use of resources by each patient cannot be predicted, but the average resource use of a group of patients belonging to the same APG can be reliably estimated. In this effort several cost accounting techniques must be implemented. One of this will be presented in our next article, taking account further international comparisons.

\section{Discussion and Conclusions}

As mentioned when introducing this paper, we tried through our research project to find best practices for EOPYY in developed health systems and international insurance funds. Our methodology included inter alia search for structural, operational and financial similarities between these health systems/organizations and ESY/ EOPYY. However, we cannot ignore unconventional approaches standing too far away from the Greek status quo. Among the next paragraphs, we represent the benchmarks arising from three different types of health systems.

The British NHS is typically a comprehensive public and low cost system [43] with many influences in Greece. The British PHC is dominated by family physicians (GPs), while the other physicians are employed in hospitals, under a strict referral system driven by GPs [43] [44]. The continuous reforms of the last thirty years resulted in a fairly "disciplined" system, simultaneously developing flexibility, competition among suppliers and a quasimarket environment [44] [45]. The upgraded role of British GPs emerged several structural proposals for the Greek case, while co-payments where the proposed referral system is violated were inspiring.

The social security approach (Bismarck model) is sufficiently represented by the German system that is primarily funded by insurance contributions [46]. This funding is provided through a series of institutions and processes that start from the Central Health Fund to individual pension funds and arrive to associations of physicians and individual physicians. In 2009, the German health insurance system was subject to a significant reform that aimed to intensify competition and ensure financial sustainability [21] [47]. AOK's global budgets were a suitable benchmark for EOPYY.

The Dutch health insurance system seems too liberal and competitive compared to the Greek one. Nevertheless, mixed reimbursement of Dutch family physicians motivated our research positively. It is the most "privatized" system in Europe while it maintains its public character [11] [33]. Particularly, each citizen is entitled to choose his/her statutory insurer and also to ensure a supplementary insurance package [48]. PHC is engrossed by GPs, who are individuals with lists of registered population and they are mainly reimbursed through mixed payments (per capita and fee-for-service) [33] [49].

EOPYY's establishment is undoubtedly the most promising reform of the last decades in Greek health insurance. However, its performance up to the 3rd quarter of 2013 doesn't seem to have met the expectations of Greek society, Greek state as well as the so called Troika (EU-ECB-IMF) yet. The organization is engaged in a vicious circle of deficits that characterize the domestic social insurance system generally. Besides, Greek PHC lacks rational organization/allocation of human resources resulting in an ostensibly under-crowded scheme. The most serious problem is the substantial absence of family physicians as the first point of reference to health services. This absence in combination with other practices in PHC provision favored an uncontrolled provision of medical examinations and diagnostic tests without evaluation on their intrinsic contribution to morbidity reduction or health status improvement.

EOPYY's establishment reform in 2011 may turn into a disaster if a PHC orientation is not adopted whereby GPs and family pediatricians control patients flow in the NHS. It is certain that a consecutive reform is needed, which would control costs and reduce the phenomenon of unjustifiable hospitalization.

Our major proposals to Greek policy makers include motivation of medical graduates to prefer general practice, rational geographic distribution of physicians, consolidation of health centers and EOPYY's units to an NHS in 
which patients prefer them to hospitals, staff restructuring by promoting health professions best suited in PHC (e.g. nurses and midwives) and last but not least development of a system evaluating the provision of PHC services.

At the same time, EOPYY's finances should move upwards by revising providers' reimbursement (expenditure adjustment) and concentrating the total public financing for health care (revenue adjustment). In other words, EOPYY should act as the main public and social financier instead of a provider.

\section{Acknowledgements}

We would like to express the deepest appreciation to J. Gounaris for providing valuable language help.

\section{References}

[1] National Organization for Healthcare Provision (EOPYY) (2013) Official Website. www.eopyy.gov.gr

[2] Polyzos, N., Kastanioti, C., Theodorou, M., Karakolias, S., Mama, M., Thireos, E., Polizoidis, P., Skamnakis, C., Tsairidis, H. and Dikaios, C. (2013) Study on Reimbursement System of Public and Private Primary Health Care Units Contracted with EOPYY. Democritus University of Thrace, Komotini.

[3] Porter, M., Pado, E. and Lee, T. (2013) Redesigning Primary Care: A Strategic Vision to Improve Value by Organizing around Patients' Needs. Health Affairs, 32, 516-525. http://dx.doi.org/10.1377/hlthaff.2012.0961

[4] Law 3918/2011

[5] Chevreul, K., Durand-Zaleski, I., Bahrami, S., Hernández-Quevedo, C. and Mladovsky, P. (2010) France: Health System Review. Health Systems in Transition, 12, 1-291.

[6] Müller, J. and Maaz, W. (2010) Der Schätzerkreis in der Gesetzlichen Krankenversicherung. Gesundheits und Sozialpolitik, 64, 20-25.

[7] Hofmarcher, M.M. and Rack, H.-M. (2006) Austria: Health System Review. Health Systems in Transition, 8, 1-247.

[8] Law 3054/2012

[9] Skroumpelos, A., Kapaki, V., Athanasakis, K., Souliotis, K. and Kiriopoulos, I. (2012) Reconstruction and Financing of Health Insurance: The National Organization for Healthcare Provision (EOPYY) Project. National School of Public Health (NSPH), Athens.

[10] Hellenic Statistical Authority (EL.STAT.) (2012) Announcement of the Results of the 2011 Population Census for the Resident Population. EL.STAT, Piraeus.

[11] Maarse, H. and Bartholomée, Y. (2007) A Public-Private Analysis of the New Dutch Health Insurance System. European Journal of Health Economics, 8, 77-82.

[12] Gerlinger, T. (2010) Health Care Reform in Germany. German Policy Studies, 6, 107-142.

[13] National Organization for Healthcare Provision (EOPYY) (2013) Unpublished data.

[14] Kontodimopoulos, N., Kastanioti, C., Thireos, E., Karanikas, H. and Polyzos, N. (2013) The Contribution of Generic Substitution to Rationalizing Pharmaceutical Expenditure in Greek Public Hospitals under Recent Economic Crisis. Journal of Pharmaceutical Health Services Research, 4, 211-216. http://dx.doi.org/10.1111/jphs.12032

[15] Anonymous (2013) Pharmacists Preparing for New Protests: Unions Condemn EOPYY for "Unacceptable, Illegal and Unconventional” Delays in Payment of Its Debts. http://www.tovima.gr/en/article/?aid=511944

[16] Athens-Macedonian News Agency (2013) Settle All Debts by End of the Year “or Else”, Samaras Warns EOPYY Fund Managers. http://www.amna.gr/english/articleview.php?id=3554

[17] Law 3235/2004

[18] Ministry of Health and Social Solidarity (MoH) (2013) ESY.net Unpublished Data.

[19] OECD (2012) Health at a Glance: Europe 2012. OECD Publishing. http://dx.doi.org/10.1787/9789264183896-en

[20] Kousoulis, A., Angelopoulou, K.-E. and Lionis, C. (2013) Exploring Health Care Reform in a Changing Europe: Lessons from Greece. European Journal of General Practice, Early Online, 1-6.

[21] Pierrakos, G. and Yfantopoulos, J. (2007) Factors That Influence the Evaluation of Primary Health Care Services. Archives of Hellenic Medicine, 24, 578-582.

[22] Oikonomidou, E., Anastasiou, F., Dervas, D., Patri, F., Karaklidis, D., Moustakas, P., Andreadou, N., Mantzanas, E. and Merkouris, B. (2010) Rural Primary Care in Greece: Working under Limited Resources. International Journal for Quality in Health Care, 22, 333-337. http://dx.doi.org/10.1093/intqhc/mzq032

[23] Markaki, A., Antonakis, N., Philalithis, A. and Lionis, C. (2006) Primary Health Care Nursing Staff in Crete: An 
Emerging Profile. International Nursing Review, 53, 16-18. http://dx.doi.org/10.1111/j.1466-7657.2006.00456.x

[24] Hellastat (2013) Sector Study: Private Diagnostic Centers. Hellastat, Athens.

[25] Yfantopoulos, J. (2007) The Welfare State in Greece. In: Metaxas, A.J., Ed., About Greece, Ministry of Press and Mass Media, Athens, 328-342.

[26] Reibling, N. and Wendt, C. (2012) Gatekeeping and Provider Choice in OECD Healthcare Systems. Current Sociology, 60, 489-505. http://dx.doi.org/10.1177/0011392112438333

[27] Greek Public Opinion (GPO) SA (2011) Nationwide Public Opinion Research: Research on Evaluation of Health Services. National School of Public Health (NSPH), Athens.

[28] Mossialos, E., Allin, S. and Davaki, K. (2005) Analysing the Greek Health System: A Tale of Fragmentation and Inertia. Health Economics, 14, S151-S168. http://dx.doi.org/10.1002/hec.1033

[29] Polyzos, N., Economou, C. and Zilidis, C. (2008) National Health Policy in Greece: Regulations or Reforms? The Sisyphus Myth. European Research Studies, 11, 91-118.

[30] Labour Institute of the Greek General Confederation of Greece (INE/GSEE) (2013) 2013 Annual Report: The Greek Economy and Employment. http://www.inegsee.gr/sitefiles/files/ekthesh-15email.pdf

[31] Polyzos, N., Karanikas, H., Thireos, E., Kastanioti, C. and Kontodimopoulos, N. (2013) Reforming Reimbursement of Public Hospitals in Greece during the Economic Crisis: Implementation of a DRG System. Health Policy, 109, 14-22. http://dx.doi.org/10.1016/j.healthpol.2012.09.011

[32] Carr-Hill, R. (1989) Allocating Resources to Health Care: RAWP (Resources Allocation Working Party) Is Dead-Long Live RAWP. Health Policy, 13, 135-144. http://dx.doi.org/10.1016/0168-8510(89)90068-7

[33] Schäfer, W., Kroneman, M., Boerma, W., Van den Berg, M., Westert, G., Devillé, W. and Van Ginneken, E. (2010) The Netherlands: Health System Review. Health Systems in Transition, 12, 1-229.

[34] Siskou, O., Kaitelidou, D., Economou, C., Kostagiolas, P. and Liaropoulos, L. (2009) Private Expenditure and the Role of Private Health Insurance in Greece: Status Quo and Future Trends. European Journal of Health Economics, 10, 467-474. http://dx.doi.org/10.1007/s10198-009-0164-3

[35] Mossialos, E. and Allin, S. (2005) Interest Groups and Health System Reform in Greece. West European Politics, 28, 420-444. http://dx.doi.org/10.1080/01402380500060460

[36] Poterba, J. (1994) A Skeptic’s View of Global Budget Caps. Journal of Economic Perspectives, 8, 67-73. http://dx.doi.org/10.1257/jep.8.3.67

[37] Mulligan, P. (2002) Capitation: The Wrong Direction for Primary Care Reform. Canadian Family Physician, 48, 233235.

[38] Fan, C., Chen, K. and Kan, K. (1998) The Design of Payment Systems for Physicians under Global Budget-An Experimental Study. Journal of Economic Behavior and Organization, 34, 295-311. http://dx.doi.org/10.1016/S0167-2681(97)00052-8

[39] Epstein, A., Lee, T. and Hamel, M. (2004) Paying Physicians for High-Quality Care. The New England Journal of Medicine, 350, 406-410. http://dx.doi.org/10.1056/NEJMsb035374

[40] Dervenis, C., Kastanioti, C. and Polyzos, N. (2013) Restructuring the Finances of the Greek Health Care System in the Era of Economic Crisis. World Journal of Surgery, 37, 707-709. http://dx.doi.org/10.1007/s00268-012-1755-1

[41] Lionis, C. and Petelos, E. (2013) The Impact of the Financial Crisis on the Quality of Care in Primary Care: An Issue that Requires a Prompt Attention. Quality in Primary Care, 21, 269-273.

[42] Goldfield, N., Averill, R., Eisenhandler, J. and Grant, T. (2008) Ambulatory Patient Groups, Version 3.0-A Classification System for Payment of Ambulatory Visits. Journal of Ambulatory Care Management, 31, 2-16. http://dx.doi.org/10.1097/01.JAC.0000304091.21087.08

[43] Boyle, S. (2011) United Kingdom (England): Heath System Review. Health Systems in Transition, 13, 1-486.

[44] Greener, I. (2009) Healthcare in the UK: Understanding Continuity and Change. Policy Press, Bristol.

[45] Crisp, N. (2011) 24 Hours to Save the NHS. Oxford University Press, Oxford.

[46] Busse, R. and Riesberg, A. (2004) Health Care Systems in Transition: Germany. WHO Regional Office for Europe on Behalf of the European Observatory on Health Systems and Policies, Copenhagen.

[47] Göpffarth, D. and Henke, K.D. (2013) The German Central Health Fund-Recent Developments in Health Care Financing in Germany. Health Policy, 109, 246-252. http://dx.doi.org/10.1016/j.healthpol.2012.11.001

[48] Roos, A.F. and Schut, F. (2012) Spillover Effects of Supplementary on Basic Health Insurance: Evidence from the Netherlands. European Journal of Health Economics, 13, 51-62. http://dx.doi.org/10.1007/s10198-010-0279-6

[49] Van der Feltz-Cornelis, C., Knispel, A. and Elfeddali, I. (2009) Treatment of Mental Disorder in the Primary Care Setting 
in the Netherlands in the Light of the New Reimbursement System: A Challenge? International Journal of Integrated Care, 8, 1-14.

\section{Appendices}

\section{List of Abbreviations}

AOK: Allgemeinen Ortskrankenkasse;

APG: Ambulatory Patient Group;

CAPI: Contrat d'Amelioration des Pratiques Individuelles;

DRG: Diagnosis Related Group;

ECB: European Central Bank;

EOPYY: National Organization for Healthcare Provision;

ESY: Greek National Health System (NHS);

EU: European Union;

FAHIF: Federation of Austrian Health Insurance Funds;

GDP: Gross Domestic Product;

GP: General Practitioner;

IKA: Private Employees’ Fund;

IMF: International Monetary Fund;

MoH: Ministry of Health;

OAEE: Entrepreneurs’ Fund;

OGA: Farmers' Fund;

OPAD: Public Employees’ Fund;

PHC: Primary Healthcare;

RAWP: Resources Allocation Working Party;

UNCAM: Union Nationale des Caisses d'Assurance Maladie;

YPAKP: Ministry of Labour and Social Security. 